\title{
Does UN Peacekeeping Prevent Communal Violence? Evidence from Disputes in Burkina Faso and Mali
}

\author{
William G. Nomikos* $\quad$ Ipek Ece Sener ${ }^{\dagger}$
}

Rob Williams ${ }^{\ddagger}$

August 10, 2021

\begin{abstract}
Research in political science has shown that UN peacekeeping operations are an important tool for ending civil war violence. However, much less is known about how UN peacekeepers affect communal violence at the level of the individual, family, or community. Given that communal disputes over local issues such as land use, cattle herding, or access to resources are the main source of instability in Africa, understanding how international actors can contribute to their resolution is a pressing concern. How does the presence of UN peacekeepers affect communal violence between civilians in conflict settings? We address this question by offering a straightforward empirical test of how UN peacekeeping patrols affect the likelihood that a communal dispute will become violent in an active conflict setting with a multidimensional peacekeeping operations. We build on the literature on communal conflicts to argue that peacekeepers deter violence against violence. To test our argument, we examine the case of Mail, the site of large-scale communal violence managed by UN peacekeepers since 2013. We employ a Geographic Regression Discontinuity Design (GRDD) around the border of Mali and Burkina Faso to estimate the causal effect of deploying peacekeepers to an area with growing communal tensions. We find that the presence of peacekeepers reduces the probability of the onset of communal violence by $17 \%$. Furthermore, we show that the magnitude of this effect increases as the number of peacekeepers deployed to a given area increase. Ultimately, our research provides robust causal evidence that UN peacekeeping works at the local level.
\end{abstract}

\footnotetext{
${ }^{*}$ Corresponding Author. Assistant Professor, Department of Political Science, Washington University in St. Louis. Email: wnomikos@wustl.edu. Website: williamgnomikos.com. Twitter: @wnomikos.

${ }^{\dagger}$ PhD Candidate, Department of Political Science, Washington University in St. Louis. Email: isener@wustl.edu.

${ }^{\ddagger}$ Postdoctoral Fellow, Weidenbaum Center, Washington University in St. Louis. Email: rob.williams@wustl.edu. Website: jayrobwilliams.com. Twitter: jayrobw.
} 